Reply

\title{
Reply to Legat, B.; Rocher, L. The Limits of Pairwise Correlation to Model the Joint Entropy. Comment on "Nguyen Thi Thanh et al. Entropy Correlation and Its Impacts on Data Aggregation in a Wireless Sensor Network. Sensors 2018, 18, 3118"
}

\author{
Nga Nguyen Thi Thanh*(D), Khanh Nguyen Kim, Son Ngo Hong and Trung Ngo Lam \\ School of Information and Communication Technology, Hanoi University of Science and Technology, \\ Hanoi 11615, Vietnam; khanhnk@soict.hust.edu.vn (K.N.K.); sonnh@soict.hust.edu.vn (S.N.H.); \\ trungnl@soict.hust.edu.vn (T.N.L.) \\ * Correspondence: ngantt@soict.hust.edu.vn
}

check for

updates

Citation: Nguyen Thi Thanh, N.; Nguyen Kim, K.; Ngo Hong, S.; Lam, T.N. Reply to Legat, B.; Rocher, L. The Limits of Pairwise Correlation to Model the Joint Entropy. Comment on "Nguyen Thi Thanh et al. Entropy Correlation and Its Impacts on Data Aggregation in a Wireless Sensor Network. Sensors 2018, 18, 3118". Sensors 2021, 21, 3729. https:// doi.org/10.3390/s21113729

Academic Editor: Jaime Lloret

Received: 21 May 2021

Accepted: 25 May 2021

Published: 27 May 2021

Publisher's Note: MDPI stays neutral with regard to jurisdictional claims in published maps and institutional affiliations.

Copyright: (c) 2021 by the authors. Licensee MDPI, Basel, Switzerland. This article is an open access article distributed under the terms and conditions of the Creative Commons Attribution (CC BY) license (https:// creativecommons.org/licenses/by/ $4.0 /)$.
In the comment, the authors have mentioned that two claims in our paper are incorrect in general. On behalf of all authors, I would like to reply as follows:

- As mentioned in our paper, claim 1 derives from [1,2] such that the correlation coefficient between one cluster and another cluster can be obtained by the smallest/largest/average correlation coefficient from any member of one cluster to any member of the other. Claim 2 is proved by using claim 1 .

- We believe that there is a class of datasets such as environmental parameters (temperature as shown in our paper) and vision data (as shown in [1]) that satisfy claim 1. The next work is to find the properties of these datasets and clarify the application range of our result.

Funding: This research received no external funding.

Conflicts of Interest: The authors declare no conflict of interest.

\section{References}

1. Dai, R.; Akyildiz, I.F. A spatial correlation model for visual information in wireless multimedia sensor networks. IEEE Trans. Multimed. 2009, 11, 1148-1159. [CrossRef]

2. Jain, A.K.; Murty, M.N.; Flynn, P.J. Data clustering: A review. ACM Comput. Surv. 1999, 31, 264-323. [CrossRef] 